\title{
TRABALHO INFANTIL PRODUTIVO E DESENVOLVIMENTO HUMANO
}

\author{
Herculano Ricardo Campos \\ Rosângela Francischini"
}

\begin{abstract}
RESUMO. O propósito deste artigo é apresentar e discutir algumas dentre as possíveis conseqüências do trabalho produtivo precoce sobre o desenvolvimento da criança, na dinâmica da vida dos adolescentes e no interior das famílias. Os dados empíricos foram buscados em vivências do trabalho por crianças e adolescentes no cotidiano de um município do interior do Rio Grande do Norte, onde há participação significativa desses sujeitos na produção de redes, nas tecelagens. A cultura de valorização/dignificação do trabalho, a ineficiência (se não inexistência) de políticas públicas voltadas para essa população e a condição de pobreza a que estão submetidas, dentre outros fatores, têm contribuído para a manutenção da exploração da mãode-obra infanto-juvenil, a despeito do ECA e dos esforços para seu combate.
\end{abstract}

Palavras-chave: trabalho precoce, infância, adolescência.

\section{CHILD PRODUCTIVE LABOR AND DEVELOPMENT}

\begin{abstract}
This paper intends to present and to discuss some of many possible consequences of the early productive labor in a child development, in the adolescent life course and inside their families. Empirical data were collected in the labor experience of adolescents and children from a town in Rio Grande do Norte state where the subjects play a relevant role in the net making production for the textile industry. A culture values labor, and an absence of public policies for this impoverished population have contributed, among other factors, to the maintenance of the exploration of children and adolescents' labor, despite the existence of the Children and Adolescent's Statute and efforts made to face this situation.
\end{abstract}

Key words: early labor, childhood, adolescence.

\section{INTRODUÇÃOO}

A preocupação com os processos de constituição/desenvolvimento do sujeito, de alguma forma e desde sempre perpassa as mais diversas correntes que foram se configurando historicamente e hoje se aglutinam no que denominamos Ciência Psicológica. No entanto, se há relativa unanimidade no que se refere ao "objeto de investigação", o mesmo não pode ser observado quando se constroem os pressupostos que fundamentam esses processos e, coerentemente com eles, os procedimentos mais apropriados para sua compreensão. Exemplo dessa condição é o recorrente debate, na bibliografia especializada, sobre a influência, mais ou menos determinante, do ambiente sobre o desenvolvimento humano.

Nesse sentido, as clássicas concepções sobre a natureza humana desenvolvidas, por um lado, por Locke (1632-1704) e Hume (1711-1776) e, por outro, por Rousseau (1712-1778), constituem-se, respectivamente, como alicerces das tradições empirista, cuja ênfase recai sobre o papel determinante do ambiente, e inatista, que acentua as características herdadas - a bondade natural, em Rousseau, por exemplo -, principalmente na Psicologia evolutiva, tradições essas cujo poder explicativo e influência no desenvolvimento dessa ciência são inquestionáveis ${ }^{1}$.

Professor-doutor, Chefe do Departamento de Psicologia e Professor do Programa de Pós-Graduação em Psicologia da Universidade Federal do Rio Grande do Norte, Pesquisador do Núcleo de Estudos Socioculturais da Infância e Adolescência - NESCIA.

Endereço para correspondência: Rua Coronel João Medeiros, 1882, Lagoa Nova, CEP 59 078- 010, Natal-RN. E-mail: hercules@ufrnet.br

\# Professora-doutora do Departamento de Psicologia e do Programa de Pós-Graduação em Psicologia da Universidade Federal do Rio Grande do Norte, Coordenadora do Núcleo de Estudos Socioculturais da Infância e Adolescência - NESCIA

1 O leitor interessado dispõe de amplo material bibliográfico a respeito.Além dos clássicos citados - Locke, Hume e Rousseau, autores como Coll, Palácios e Marchesi (1995), Piaget (1964, 1967, 1984), Bruner (1965), Flavell (1975), Biaggio (1988), dentre outros. 
No entanto, cabe-nos apontar que, se o debate em torno desses modelos explicativos - empirista e inatista - ainda persiste, atualmente lhes são acrescentados enfoques teóricos de caráter interacionista, que ultrapassam as fronteiras por eles delimitadas e sinalizam para novas perspectivas interpretativas do desenvolvimento humano, dentre as quais se destacam: a etológica, com ênfase em pesquisas em ambientes naturais; a ecológica, representada, sobretudo, por Bronfenbrenner (1992, 1996) e, por fim, a perspectiva sócio-históricocultural, cujo destaque vem se acentuando, principalmente a partir da década de 70 , com o "descobrimento" das obras de seu principal teórico, Vygotsky $(1984,1988,1996,1997)^{2}$.

Duas contribuições principais ao estudo do desenvolvimento são devidas, segundo Coll (1995), à perspectiva etológica. A primeira é o destaque ao conceito de ambiente de adaptação e ajustes necessários da conduta às exigências que esse ambiente apresenta, o segundo, a importância da prática de observação em ambientes nos quais a conduta se produz. Esta última característica está presente, também, em pesquisas que assumem a perspectiva ecológica. No entanto, ainda segundo o autor acima citado, à observação em ambientes naturais devem ser acrescidas a preocupação com os múltiplos fatores que influenciam o desenvolvimento, a consideração para com as influências mútuas criança-ambiente e, por fim, a crença de que realidades não imediatamente presentes exercem influência sobre o comportamento da criança.

Quanto à última perspectiva, no interior da qual se procurará desenvolver as reflexões deste estudo, o processo de desenvolvimento consiste na internalização de regras, valores, modos de pensar e de agir ocorrentes nas interações sociais do cotidiano dos sujeitos, nas práticas sociais e discursivas que permeiam as instituições sociais (família, escola, igreja, trabalho...) e os meios de comunicação. Nessas interações, recorre-se aos instrumentos de mediação semiótica disponíveis na sociedade, entre os quais a

2 Em relação às publicações originais dessas obras, temos a esclarecer: $1^{\circ}$ ) as de 1984 e 1996 reúnem obras publicadas originalmente separadas. As datas dos ensaios que as compõem são, portanto, diferenciadas; $2^{\circ}$ ) A obra de 1988 é uma compilação de textos de Leontiev, Luria e Vigotski, publicados originalmente em datas diferenciadas; $3^{\circ}$ ) a obra de 1997 foi publicada originalmente em 1934. Em 2001, a Editora Martins Fontes lançou A Construção do Pensamento e da Linguagem, texto integral de Pensamento e Linguagem, traduzido do russo por Paulo Bezerra. No presente trabalho, recorre-se à versão em francês, traduzida do russo por Françoise Sève. linguagem ocupa posição privilegiada. Da afirmação acima destacam-se, portanto, o papel das interações sociais, o caráter mediado dessas interações e a posição da linguagem enquanto instrumento principal de intercâmbio com o outro. Em relação ao primeiro aspecto, a "lei genética geral do desenvolvimento cultural" explicita a verdadeira dimensão do processo de internalização. Nas palavras do autor:

Qualquer função no desenvolvimento cultural da criança aparece duas vezes, ou em dois planos. Primeiro, ela aparece no plano social e, depois, no plano psicológico. Primeiro, aparece entre as pessoas como uma categoria interpsicológica, e depois dentro da criança como uma categoria intrapsicológica. (...) Não é necessário dizer que a internalização transforma o próprio processo e muda sua estrutura e funções (Vygotsky, 1981, p. 163).

O processo de internalização, no entanto, implica na utilização de instrumentos técnicos e sistemas de signos enquanto mediadores da relação do homem com o ambiente, com o outro. Particular atenção, conforme sinalizado anteriormente, é dada ao signo lingüístico. Consideradas um dos temas mais complexos no interior da psicologia sócio-histórica, as relações entre a linguagem e o desenvolvimento do pensamento é objeto de reflexão sobretudo no sétimo capítulo de Pensée \& langage (1997). Dessa reflexão, interessa-nos, neste trabalho, acentuar o papel da linguagem na constituição da consciência. Enquanto prática social, a linguagem é considerada atividade constitutiva do ser humano. "A linguagem (...) regula a atividade psíquica, constituindo a consciência, porque é expressão de signos que encarnam o sentido com elemento da cultura. Sentido que exprime a experiência vivida nas relações sociais, entendidas estas com espaço de imposições, confrontos, desejos, paixões, retornos, imaginação e construções." (Kramer, 1994, p. 107).

Com essas idéias em mente, procura-se, neste estudo, examinar e discutir os impactos do trabalho precoce $^{3}$, e o faremos a partir de três ângulos de observação: $1^{\circ}$.) o desenvolvimento da criança; 2.) efeitos do trabalho precoce no interior das famílias, e,

\footnotetext{
Por trabalho precoce não se entende, neste estudo, qualquer atividade desenvolvida pelas crianças, como as atividades domésticas em conjunto com a família etc., em relação às quais alguns autores atribuem certo caráter pedagógico. Ao contrário, o sentido aqui atribuído encontra-se diretamente relacionado com a inserção em atividades produtivas, geradoras de valor - e de exploração.
} 
por fim, $3^{\circ}$.) implicações sobre a dinâmica de vida dos adolescentes trabalhadores.

Nesta perspectiva, tomam-se como dado empírico os resultados de uma pesquisa realizada no município de Jardim de Piranhas, localizado no interior do Rio Grande do Norte, cujas características são descritas a seguir.

\section{O CENÁRIO E UM POUCO DA HISTÓRIA}

Jardim de Piranhas ${ }^{4}$ dista $315 \mathrm{~km}$. de Natal, capital do Estado do Rio Grande do Norte, sendo cortado pelo rio Piranhas, fator de desenvolvimento regional. A região onde está situado o município tinha tradicionalmente como atividade principal a agropecuária e, dessa forma, uma ocupação populacional concentrada principalmente na zona rural. Com os ininterruptos anos de forte seca, sendo assim forçados a abandonar o cultivo da terra e a criação de animais, agricultores e suas famílias passaram a migrar para centros urbanos, tendo sido esse município um dos principais destinos desses imigrantes. Tal escolha deveu-se, em grande parte, ao fato de ter se desenvolvido em Jardim uma indústria de tecelagem de grande importância para a região, pelo número de empregos gerados e pelo total de recursos movimentado, que, ao menos a princípio, aparecia como uma possibilidade de absorver a mãode-obra desses agricultores, agora sem terra, sem casa e sem trabalho.

Em decorrência da migração aumentou o número de famílias dotadas de parcos recursos financeiros e com precário acesso a bens públicos como saúde, educação, saneamento e habitação. Observaram-se, então, no município, significativas modificações no tecido social, no interior do núcleo familiar, na estrutura do trabalho e, particularmente, no comportamento dos jovens. O componente salário do custo do trabalho no setor produtivo caiu a níveis significativamente baixos. Sob tais condições os trabalhadores se viram na contingência de lançar mão da força de trabalho de suas crianças, as quais foram contratadas, informalmente, para realizar atividades periféricas - e de menor valor - na cadeia produtiva de

4 De acordo com o Atlas da exclusão social no Brasil (Pochman \& Amorim, 2003), o município de Jardim de Piranhas situa-se no $3353^{\circ}$ lugar do ranking da exclusão, apresentando os seguintes índices: pobreza $(0,274)$; juventude $(0,645)$; alfabetização $(0,634)$; escolaridade $(0,279)$; emprego formal $(0,093)$; violência $(0,964)$; desigualdade $(0,024)$ e exclusão social $(0,388)$. (p.140). certos produtos, inserindo-se no mercado enquanto trabalhadores precarizados.

Além de ser decorrente da pobreza generalizada, a exploração do trabalho infantil no interior das tecelagens reflete o baixo grau de regulação a que está submetido o trabalho no município e o alto nível de desorganização dos trabalhadores. Se, para os empresários, a inserção precoce das crianças em atividades produtivas é justificada em face do barateamento dos custos de produção e crescimento dos lucros, do ponto de vista das crianças e de suas famílias ela tem sido justificada por liberar os adultos para outros trabalhos, complementar a renda familiar, prevenir situações de envolvimento com a marginalidade, obter recursos para o custeio de objetos pessoais, assim deixando transparecer a confluência dos interesses das famílias e dos empresários.

No ano de 1997, a fiscalização da Delegacia Regional do Trabalho e Emprego do Rio Grande do Norte (DRTE/RN, Brasil: 1998a) encontrou trabalhando, diretamente nas tecelagens de Jardim de Piranhas, um grupo de 123 crianças e adolescentes com idade inferior a 14 anos. Em decorrência, na intenção de suprimir o trabalho infantil no município, em 1998 foi montado um programa de atendimento Jardim Esperança -, anterior ao Programa de Erradicação do Trabalho Infantil (PETI), para onde foram encaminhados aqueles trabalhadores infantis. Uma bolsa foi prometida a suas famílias, como forma de compensar a perda do rendimento auferido pelas crianças.

Contudo não obstante, visto que as bolsas só começaram a ser pagas em meados de 2000, depois de iniciadas as ações do PETI, de maneira geral permaneceu e se agravou o quadro do trabalho de crianças, embora com alguns ajustes. Ou seja, afastadas das indústrias diante da pressão da fiscalização, é no interior das residências que se passa a observar sua inserção precoce no trabalho produtivo. Logo, não é de estranhar que, no mesmo ano da criação do Jardim Esperança, as estimativas apontavam para a existência de 400 crianças trabalhando sob condições precárias. Como não é difícil concluir, essas condições tiveram impactos consideráveis em várias esferas da dinâmica do município.

\section{IMPACTOS DO TRABALHO PRECOCE NO DESENVOLVIMENTO DAS CRIANÇAS}

Em outro contexto deste artigo afirma-se que, no interior da perspectiva sócio-histórica, o 
desenvolvimento humano é entendido como um processo de internalização de regras, de valores e de modos de pensar e de agir que ocorre nas interações sociais das quais o sujeito participa em seu dia-a-dia. Nesse sentido, como pensar esse processo em crianças e adolescentes que vivenciam, em seu contexto social, a realidade do trabalho precoce? $\mathrm{Na}$ tentativa de refletir sobre ele, ao menos dois aspectos nos são colocados. $\mathrm{O}$ primeiro deles diz respeito à internalização do sentido atribuído ao trabalho, pelos adultos, nesse contexto. O segundo, aos impactos dessa prática no desenvolvimento dos sujeitos que a ela estão submetidos/expostos cotidianamente.

Iniciando pela questão do sentido atribuído ao trabalho, pelos adultos, pode-se depreender dos depoimentos apresentados pelos sujeitos entrevistados que, do ponto de vista das famílias, em face do quadro de carências a que se encontram submetidas, o trabalho infantil já foi incorporado à sua rotina, de modo que tanto não é questionado quanto é reiteradamente solicitado. Assim, o contexto de pobreza em que estão inseridas as famílias forja um discurso de justificação da inserção precoce no trabalho, naturalizando-o, discurso que tanto serve para negar os evidentes prejuízos às crianças quanto afirmar a importância do emprego delas pelos capitalistas 5 .

Em Jardim de Piranhas, ademais, tal discurso também é utilizado para justificar a ociosidade de um grande número de homens adultos, excluídos do emprego formal em face das características que assumiu a precarização do trabalho, na região. Sob essas condições, as relações de exploração que se efetivam pelo trabalho, por oferecerem as chances de subsistência da família e de ocupação dos meninos e meninas, vistas de um prisma invertido, são consideradas benéficas.

Esta não é, entretanto, uma situação nova, tampouco restrita a Jardim. Ao tratar do desenvolvimento do capitalismo, desde o século XVIII, Marx (1867/1996) já denunciava os acordos levados a termo pelos capitalistas, negociados junto a abrigos suspeitos ou familiares famintos. Por meio deles as crianças eram entregues à mais completa exploração, justificada pelo aprendizado de um ofício, de que se valeriam no trabalho desenvolvido, e pelas dificuldades da família para se manter e mantê-las. Da mesma forma, ao tratar da evolução do industrialismo no Brasil, no início do século XIX, o estudo de Dulles (1977) permite observar algumas das situações anteriormente constatadas na Inglaterra, particularmente

\footnotetext{
A esse respeito ver Engels, 1986.
}

o aluguel de crianças. Os familiares que as entregavam aos capitalistas, em face do alto grau de pobreza a que estavam submetidos, consideravam tais empresários benfeitores da família e das próprias crianças ${ }^{6}$.

As informações contidas nos depoimentos permitem observar a particularidade dos dados revelados por inúmeros levantamentos, de que é exemplo a Pesquisa Nacional por Amostragem Familiar - PNAD -, realizada pelo Instituto Brasileiro de Geografia e Estatística - IBGE (1999). Os exemplos consubstanciados nos depoimentos dos sujeitos $^{7}$ indicam como são socialmente construídos os índices de pobreza, exploração do trabalho infantil, baixa escolaridade, má nutrição, mortalidade infantil etc., num movimento circular em face do qual é compreensível sua naturalização. As famílias, submetidas às mais duras condições de vida, ao buscarem em estratégias como o trabalho das crianças a mitigação dos seus males, por um lado aprofundam a miséria em que vivem e, por outro, garantem a base para a reprodução do mesmo quadro.

$\mathrm{O}$ depoimento abaixo ilustra a precocidade com que as crianças são inseridas no trabalho e a naturalização desse discurso no interior de suas famílias. De acordo com a mãe de uma família,

Quase todos eles [os filhos] começaram a passar $^{8}$ com sete anos [de idade]. Tem um com nove anos, que já passa; uma menina com 12, que começou também a passar bem novinha e tem um com 14, que quando começou a passar rede tava na faixa dos oito anos. Tudinho eu comecei a botar pra passar rede perto de oito anos.

É curioso como essa mãe aparenta não se dar conta da dramaticidade do quadro em que está inserida e para onde arrasta seus filhos, tratando com naturalidade um problema que se repete e vem sendo combatido há séculos. A seqüência desse mesmo depoimento nos dá a exata dimensão do segundo

\footnotetext{
Também a esse respeito ver Engels (1986).

7 Os depoimentos aqui relatados foram extraídos do corpus de uma pesquisa realizada por Campos (2001), um dos autores deste artigo, no contexto dos estudos do seu doutoramento, que buscou "analisar algumas das condições sob as quais se observa o fenômeno do trabalho infantil nos países capitalistas", tendo a realidade de Jardim de Piranhas como palco para ilustração/discussão dessa questão. Assim, os segmentos de depoimentos aqui constantes são recortes daqueles recolhidos por ocasião da constituição do corpus da pesquisa de doutorado.

8 O termo "passar" refere-se à atividade de confecção de um adereço para as redes de dormir.
} 
aspecto que apontamos anteriormente, qual sejam as conseqüências do trabalho precoce na saúde das crianças. Segundo a entrevistada,

\begin{abstract}
"Quando passava a mamucaba", os meninos reclamava demais, que sentia muita dor nos quadril, que sentia dor de cabeça; tinha dias que alguns deles não conseguia passar, são tudo pequeno. Eu nunca levei eles pro médico, por conta das dores que eles sentiam no espinhaço".
\end{abstract}

Um outro depoimento segue a mesma direção. Veja-se:

\begin{abstract}
"(...) os meninos se queixam do espinhaço", e um deles "tem uma perna menor, por causa da mamucaba". Ela é "doente dos ossos", já tendo tomado injeção de "dexacitoneurin" e se encontra tomando "chá de casca de pau, para curar inflamação".
\end{abstract}

Embora no primeiro depoimento as referências ao trabalho das crianças sejam feitas a um passado cuja condição, subentende-se, não mais persiste na família da entrevistada, podemos afirmar que o mesmo não se passa em todas as famílias. Ainda no início de 2001, constatou-se que crianças com até nove anos de idade confeccionavam, nas suas residências, a mamucaba, valendo-se de teares manuais, rudimentares, em condições que lembram as referências ao modo de produção artesanal. As atividades domésticas, por encontrarem-se protegidas da fiscalização do Ministério do Trabalho, possibilitam que os pais imponham às crianças jornadas muitas vezes proibitivas até mesmo para um adulto, em condições de trabalho extremamente prejudiciais.

Além dos efeitos que a rotina descrita pode trazer à vida das pessoas envolvidas, as condições mesmas nas quais as atividades de trabalho são desempenhadas, ou seja, o fio em si, que circula no ar e adere a tudo, o calor das latadas ${ }^{10}$ improvisadas com amianto, o chão de barro batido, as refeições instáveis e as incômodas posturas assumidas por horas ininterruptas, trazem irremediáveis comprometimentos da coluna, do equilíbrio e do desenvolvimento físico. Foram identificados, também, significativos índices de tristeza, desânimo e apatia entre os trabalhadores precoces, explicados pela monotonia das tarefas e dispêndio de energia que requerem. (Brasil, 1999). Por

\footnotetext{
9 Um pequeno adereço para as redes, tecido para proteger os cordões do punho cuja confecção é definida pelos moradores do município como atividade de "passar rede".

10 Terraços, áreas, espaços externos às residências.
}

estarem submetidas a uma carga de trabalho estafante e de alta responsabilidade até para um adulto, há um comprometimento da organização psicológica das crianças, de modo que o adulto que serão não terá, muito provavelmente, o equilíbrio emocional suficiente para fazer frente às novas demandas que lhe serão postas.

À debilitação da sua condição física acrescente-se um estado de fadiga e falta de disposição (e tempo) para engajamento em outras atividades, déficit de atenção e de concentração e restrições às possibilidades de relações sociais. Em decorrência, as crianças ficam privadas de brincar, ou seja, de uma das atividades que mais contribuem para o desenvolvimento saudável de aspectos físicos, cognitivos e sociais. Segundo Vygotsky (1984), no exercício de atividades lúdicas a criança "faz o que mais gosta de fazer, porque o brinquedo está unido ao prazer". (1984, p. 113). Ainda de acordo com esse autor, dois outros aspectos determinam a importância do brincar. O primeiro é ser uma atividade que favorece a maturação de certas necessidades da criança, estando assim, diretamente associado ao desenvolvimento; o segundo, possibilitar à criança em idade pré-escolar a efetivação de desejos não realizáveis no mundo real.

Em relação às possibilidades engendradas através de e nas atividades lúdicas, Vygotsky (1984) assinala que nestas se dá a criação, por parte da criança, de uma situação imaginária em que as relações/vinculações entre o objeto, as ações sobre ele e seu significado podem ser diferenciadas daquelas habitualmente concebidas. Assim, a possibilidade de operar nessas situações imaginárias "é a primeira manifestação da emancipação da criança em relação às restrições situacionais" (p. 113) ${ }^{11}$.

Considerando que, como sinalizado por Jobim e Souza (2001), a psicologia do desenvolvimento "formula os ideais para o desenvolvimento, providencia os meios para realizá-los e, mais do que tudo isso, acaba por desenvolver as crianças, os adolescentes e nós mesmos - adultos - com base em determinados enquadramentos, participando de nossa formação como sujeitos e como objetos" (2001, p. 41), como pensarmos a infância dos sujeitos deste estudo?

\footnotetext{
11 A importância da brincadeira no desenvolvimento humano está presente em vários outros teóricos, no interior da Psicologia. Dentre eles, remetemos o leitor para Winnicott (1982), Piaget (1964), Wallon (1975, 1979). Igualmente, o Referencial Curricular Nacional de Educação Infantil (Brasil, 1998) aponta que o "brincar é uma das atividades fundamentais para o desenvolvimento da identidade e da autonomia. (...) Nas brincadeiras as crianças podem desenvolver algumas capacidades importantes, tais como a atenção, a imitação, a memória, a imaginação". (1998, p. 12).
} 
Em decorrência das condições de existência a que estão submetidas, certamente não se enquadram no "ideal de infância" preconizado por algumas vertentes tradicionais da Psicologia do Desenvolvimento. São, antes, sujeitos que não só interiorizam os elementos de seu universo, mas também vivenciam uma infância em que não há lugar para a singularidade exercida na escolha ou prazer daquilo que fazem. Assim, determinados aspectos coercitivos da "dura" realidade (dentre eles, o do trabalho) que, imaginariamente, não encontrariam eco na infância, ocupam, desde cedo, lugar na existência desses sujeitos. É possível concluir, então, que a vida dessas crianças as leva a se identificar muito mais com os adultos que com os modelos configurados para a infância por parcela da Psicologia.

Quando se pensa na escola em um contexto como esse, o fracasso acadêmico aparece como o resultado mais esperado, tendo-se em vista as condições nas quais se encontram as crianças trabalhadoras. Objeto de investigação em inúmeras pesquisas, o fracasso escolar, manifesto, principalmente, nos altos índices de evasão e repetência das crianças oriundas das camadas desfavorecidas da população, continua sendo uma realidade no sistema educacional brasileiro. $\mathrm{O}$ objetivo de "conseguir, antes de 1999, a escolarização de todas as crianças em idade escolar, oferecendo-lhes uma educação geral mínima com duração de 8 a 10 anos", estabelecido no Projeto Principal de Educação para América Latina e Caribe, a partir da Conferência Regional de Ministros da Educação dos países que compreendem essas regiões (Ferreiro, 1992, p. 7-8), está longe de ser alcançado.

Em análise do Documento Base do Congresso Brasileiro de Alfabetização (citado por Klein, 1997), o Grupo de Estudos e Trabalhos em Alfabetização ressalta: "O fato mais marcante apontado pelo diagnóstico do sistema de ensino brasileiro é sua improdutividade, expressa nas elevadas taxas de evasão e repetência entre as crianças e jovens que chegam a freqüentar as escolas. A repetência na primeira série do primeiro grau, (...) alcança mais da metade das crianças. (...) A cada ano, através da repetência e da evasão, milhões de crianças são 'expulsas' do ensino básico, particularmente da rede pública” (Klein, 1997, p. 22).

$\mathrm{Na}$ Região Nordeste, os índices escolares apontam para uma desigualdade considerável em relação à Região Sudeste: "a proporção de analfabetos no grupo etário de 10-14 anos e no de 15-17 anos é de 5 a 6 vezes maior no Nordeste que no Sudeste" (Azevedo, 1994, p. 34). Não destoando do quadro identificado na região, o município de Jardim de Piranhas apresenta uma situação de escolarização extremamente precária.
Os dados fornecidos pela Secretaria Estadual de Educação/RN, constantes das Tabelas 15 e 16, abrangem o período de 1996 a 1998, da primeira à oitava séries do Ensino Fundamental, compreendendo as escolas situadas nas zonas urbana e rural. $\mathrm{Na}$ Tabela 1 observam-se os índices de repetência, enquanto na Tabela 2, os de evasão.

Tabela 1. Taxa de Repetência (\%) por Série, no Ensino Fundamental de Jardim de Piranhas/Rn.

\begin{tabular}{ccccccccc}
\hline Série & $\mathbf{1}^{\mathbf{a}}$ & $\mathbf{2}^{\mathbf{a}}$ & $\mathbf{3}^{\mathbf{a}}$ & $\mathbf{4}^{\mathbf{a}}$ & $\mathbf{5}^{\mathbf{a}}$ & $\mathbf{6}^{\mathbf{a}}$ & $\mathbf{7}^{\mathbf{a}}$ & $\mathbf{8}^{\mathbf{a}}$ \\
\hline 1996 & 45,37 & 26,51 & 11,57 & 9,9 & 14,17 & 12,89 & 7,96 & 13,16 \\
1997 & 46,52 & 20,75 & 9,89 & 7,14 & 14,94 & 5,13 & 3,55 & 2,83 \\
1998 & 46,90 & 20,74 & 10,87 & 7,11 & 14,94 & 5,13 & 3,55 & 2,83 \\
\hline
\end{tabular}

Fonte: Secretaria Estadual de Educação/RN

Os números acima refletem uma tendência nacional, qual seja uma alta concentração de retenção na primeira e quinta séries do Ensino Fundamental. Observe-se, entretanto, que estes altos índices de repetência refletem, igualmente, as desigualdades sociais entre as regiões brasileiras, confirmando a posição desfavorável que o Nordeste ocupa em relação às outras regiões do país. Ou seja, as médias de $46 \%$ e $14 \%$ (da primeira e quinta séries respectivamente) apresentadas nas Tabelas 1 e 2 são mais altas que as médias de outras regiões brasileiras.

Tabela 2. Taxa de Evasão (\%) por Série, no Ensino Fundamental de Jardim de Piranhas/ $\mathrm{Rn}^{12}$.

\begin{tabular}{ccccccccc}
\hline Série & $\mathbf{1}^{\mathbf{a}}$ & $\mathbf{2}^{\mathbf{a}}$ & $\mathbf{3}^{\mathbf{a}}$ & $\mathbf{4}^{\mathbf{a}}$ & $\mathbf{5}^{\mathbf{a}}$ & $\mathbf{6}^{\mathbf{a}}$ & $\mathbf{7}^{\mathbf{a}}$ & $\mathbf{8}^{\mathbf{a}}$ \\
\hline 1996 & 26 & 12,6 & 12,69 & 15,10 & 27,56 & 21,13 & 22,12 & 20,18 \\
1997 & 15,67 & 7,18 & 6,88 & 7,56 & 19,92 & 16,92 & 10,64 & 8,49 \\
1998 & 15,67 & 7,18 & 6,88 & 7,56 & 19,92 & 16,92 & 1,64 & 8,49 \\
\hline
\end{tabular}

Fonte: Secretaria Estadual de Educação/RN

Da mesma forma que a Tabela 1 , a Tabela 2 apresenta altos índices de evasão no município, especialmente na primeira série do Ensino Fundamental. Em relação às últimas séries (quinta à oitava) há uma particularidade: índices elevados perpassando todas estas séries. A interpretação destes dados sugere que os índices podem estar refletindo a inserção desta população estudada no mundo do trabalho, uma vez que a faixa etária estimada fica em torno dos 11 aos 15 anos.

12 Note-se que os índices referentes aos anos 1997 e 1998 são idênticos. Esclarecemos que os mesmos foram fornecidos pela Secretaria Estadual de Educação/RN. 
De acordo com a DRT/RN (Brasil, 1998a), dos 446 empregados na indústria têxtil que trabalhavam em jornada superior a 8 horas diárias, apenas 100 eram estudantes, ao passo que 291 pararam de estudar. Excetuando-se aqueles com o ensino médio ou o curso superior concluídos, há um total de 425 empregados fora da escola. Alguns deles, com idade entre 15 e 17 anos, alegam que o desinteresse ou o trabalho foi a razão para tal decisão.

Outros dados mais recentes, apresentados no relatório do MTE/OIT (Brasil,1999), apontam para o aprofundamento dessa problemática, na medida em que mais de $70 \%$ das crianças e adolescentes do município estão em série inadequada à idade. Além disso, tal documento revela que mais de $60 \%$ da população infantojuvenil são repetentes de pelo menos um ano, e que 85,9\% dos pais (chefes de família) não têm escolaridade ou têm, no máximo, três anos de estudo, indicando a existência de um ciclo repetitivo entre pais e filhos no tocante à questão da baixa escolaridade.

Em acréscimo, é importante informar que, no mesmo ano de 1996, 100\% dos adolescentes maiores de 14 anos, matriculados na rede de ensino municipal, encontravam-se cursando entre a primeira e quarta séries do Ensino Fundamental, levando-nos a crer que a irregularidade da trajetória escolar dessa população pode estar diretamente associada à inserção no trabalho precoce.

O município de Jardim de Piranhas apresenta, pois, um quadro nada alentador: $58,1 \%$ da renda familiar são produzidos por uma força de trabalho composta por crianças e adolescentes que freqüentam a escola de forma irregular, bem como por aqueles, juntamente com adultos, que nunca a freqüentaram. (Brasil, 1998a; 1999).

As considerações acima apontam, assim, para a necessidade de se considerar, além dos irremediáveis danos à saúde, o comprometimento no processo de escolarização. De maneira geral, os depoimentos aqui descritos ilustram e ressaltam o ingresso tardio no percurso, as constantes desistências, a reincidência das reprovações na série inicial e, perigosamente, a incapacidade dos adultos para entender que essa situação se deve ao trabalho.

Essa condição pode ser ilustrada, também, com a seguinte observação.

Em uma das famílias entrevistadas, dos 7 filhos em idade escolar, apenas um ainda não viveu a experiência da desistência ou da reprovação. No ano de 2000, a mãe alega: "Júnior desistiu da escola porque a situação da família estava ruim e não tinha merenda na escola: aí ele vinha passar rede em casa".
Nesse contexto, reprovação e desistência são tãosomente explicadas como decorrentes de brincadeiras, desatenção, falta de interesse das crianças. Ainda que tais alegações sejam procedentes, elas parecem não depor contra os pequenos trabalhadores mas, ao contrário, acentuar o grau de influência maléfica do trabalho sobre seu estado de crianças, sua infância. As famílias não conseguem entender que, ante o trabalho precoce, a estada na escola representa o único momento em que é possível a elas encontrar os colegas, conversar, brincar etc.

Reiterando as estatísticas que associam baixa escolaridade com pobreza, bem como expressando a incapacidade para identificar os reais motivos da dificuldade mostrada pelas crianças para obterem sucesso na escola, informa uma das entrevistadas:

\begin{abstract}
"Eles [os filhos] já foram reprovados muitas vezes. $\mathrm{O}$ de 14 anos fez a primeira série num sei quantos anos; agora mesmo que ele veio passar. Outro, foi reprovado na primeira série, mas já vai fazer a terceira. A menina tá na quarta [série]. Muitas vezes eles desistiam, eles mesmo queria desistir. Aí, eu comecei a castigar eles, dizer que não podiam desistir, aí eles ficaram [na escola]. O mais velho nunca desistiu; ele fez a primeira [série] com 11 anos, passou, depois começou a estudar o supletivo e todos os anos ele passa no supletivo; agora ele já vai fazer o $1^{\circ}$ ano do $2^{\circ}$ grau [primeira série do ensino médio]. Mas, já a menina que é encostada a ele [apenas um ano mais nova] desistiu na quarta série: noivou, casou e desistiu. Eu acho que eles são reprovados na escola por falta de interesse deles, porque não liga de aprender. Eu tiro pelo mais velho, que tem interesse e nunca foi reprovado. Ele trabalha, chega do serviço, toma banho e vai de carreira pra escola. Esses outros vão todos os dias, mas eles não se interessam, começam a brincar e não ligam de aprender."
\end{abstract}

A exemplo do que se observou com relação às crianças, o quadro identificado em Jardim de Piranhas também implica sérias consequiências sobre a vida dos adolescentes. É este o aspecto que focalizaremos a seguir, e, de modo a tornar mais claras nossas observações, descreveremos, inicialmente, mais alguns detalhes do contexto do município.

\section{DINÂMICA FAMILIAR}

Visto que a grande maioria dos homens adultos que migraram para a cidade só dispunha de experiência com o trato da terra e dos animais e 
considerando-se as demandas especializadas da indústria, lhes faltaram os empregos na cidade. Por outro lado, dada a tradição da indústria local de empregar crianças em atividades que não requeriam qualificação, era razoavelmente fácil encontrar uma colocação para os filhos pequenos.

No mesmo processo, se as crianças trabalhavam em atividades menos importantes, era aos adolescentes que se destinavam os postos de trabalho mais especializados e melhor remunerados que surgiam, tanto mais quanto se aproximasse o final de cada ano, quando crescia a demanda do comércio pelos produtos lá confeccionados. Ainda que não tivessem experiência com as atividades industriais, os adolescentes tinham mais disponibilidade para as duras jornadas e maior facilidade para o aprendizado, que seus pais, já cansados da dura lida no campo, não mais se dispunham a enfrentar. Por fim, dada a experiência adquirida pelas mulheres com o trabalho realizado em casa, para elas também não faltava trabalho - na residência.

Em decorrência dessa situação, ainda hoje é significativo o contingente de homens adultos ociosos, auferindo pequena renda com trabalhos eventuais como serventes de pedreiro, vendedores de frutas ou verduras etc. Seu lugar de chefes de família está mantido por força dos papéis sexuais, muito embora sua função de mantenedores tenha sido repassada para os demais membros da família, particularmente às crianças e aos adolescentes. Estes, em decorrência da responsabilidade que lhes é atribuída e do status a que foram alçados pelo seu trabalho, subvertem o papel dos pais na estrutura familiar. Os depoimentos colhidos junto a algumas mulheres, mães de família subcontratadas pelas tecelagens para desenvolver a mamucaba em suas casas, são profundamente ilustrativos dessa realidade.

Esclarece Dona Maria dos Cordões que seu marido, antes de migrarem para Jardim de Piranhas, há dez anos, agricultor no interior da Paraíba morando "de favor" em um sítio -, comprometeu "o espinhaço" lidando com animais e agora não tem mais condições de trabalho diário. Planta, para subsistência, no quintal da sua casa, trabalhando dois dias por semana, apenas. Na mesma perspectiva, informa Dona Neuzete que seu esposo,

"há mais de um ano, está parado. Ele
trabalhava de agricultura lá no sítio, mas aqui
está parado; também por causa de um
problema nos rins. No fim de semana, ele
compra umas batatas pra revender, na feira".

Da mesma forma Cordélia, ex-coordenadora do primeiro programa de atendimento, nascida no município e nele morando desde menina, profunda conhecedora da realidade das famílias em que há crianças e adolescentes trabalhadores, afirma que,

\begin{abstract}
"Na maioria das famílias que vieram da zona rural e até de outras cidades o homem, o chefe de família, fica ocioso e a mulher é quem trabalha com os filhos, dentro da própria casa (...) Isso vicia tanto, que após um tempo sem trabalhar o chefe de família não quer mais trabalhar e não aceita a criança sair do trabalho."
\end{abstract}

Como pode ser visto nos depoimentos anteriores, a situação socioeconômica de Jardim de Piranhas promove uma reorganização na estrutura familiar, alterando funções e o status de seus membros e, conseqüentemente, a forma como cada um deles se vê e também como vêem um ao outro. Nesse cenário há uma total inversão de papéis, aparecendo o adolescente como o membro de mais status e "poder". É quem tem o emprego melhor, quem ganha mais, quem provê mais ao sustento familiar e - pode se dizer também - quem tem mais liberdade na família, por ser quem tem mais dinheiro. Alguns deles chegam a ganhar até mais de quatro salários-mínimos por mês.

É interessante comentar que a mudança de status do adolescente na família não ocorre apenas como resultado de sua ascensão financeira, mas também por um deslocamento de função da figura paterna. Diferentemente de outras realidades, em que o sustento da família recai sobre a mãe e os filhos em decorrência da ausência do pai, em Jardim de Piranhas o pai está presente, embora não ocupe o lugar de provedor da família. Esta mudança de lugar pôde ser constatada durante o desenvolvimento deste estudo, por exemplo, quando da realização de entrevistas. Naquela oportunidade, em $100 \%$ das famílias visitadas, a pessoa que respondia era a mulher, a mãe e não o marido, o pai, apesar de freqüentemente ele se encontrar em casa. Tal deslocamento do homem, do pai, de seu lugar de mantenedor, pode implicar, também, sua ausência como orientador, como modelo para os filhos.

\section{TRABALHO PRECOCE E OS ADOLESCENTES}

As mudanças no interior das famílias especificadas acima, provocadas pela entrada precoce dos adolescentes no mundo do trabalho, representam, para eles, uma inserção artificial na vida adulta. 
Nessas condições, independência financeira pode ser experimentada como independência emocional e social por um indivíduo que, na verdade, ainda está se descobrindo, está em plena construção de identidade, que ainda precisaria de limites e de orientação e, efetivamente, ainda não viveu o suficiente para ter maturidade física, cognitiva, emocional ou social para o exercício das funções por ele assumidas.

$\mathrm{Na}$ comunidade estudada os jovens, embalados com os ganhos decorrentes do trabalho por produção, que variavam de 400 a 600 e até 800 reais (note-se que o valor do salário-mínimo, a partir de 01 de maio de 1998 , passou a ser $\mathrm{R} \$ 130,00)$, tanto assumiram papel preeminente no interior das famílias, para onde destinavam parte da renda auferida, quanto passaram a ser considerados, no município, uma força consumidora de produtos como roupas "de marca", perfumes, bebidas etc. e de serviços como lanchonetes, bares, boates etc. Na esteira dessa realidade, tornou-se preocupante o número de consumidores de álcool e outras drogas e de prostitutos e prostitutas entre eles, numa clara evidência de que, além dos danos físicos e mentais, seu trabalho também os compromete sob o ponto de vista da moral e da educação.

O lugar a que foram alçados, pela disponibilização de recursos decorrentes de atividades que não exigiam especialização, também resultou em forte desvalorização da escola. Neste pormenor, eles eram reforçados pelas atitudes dos empresários, para muitos dos quais um importante critério a ser considerado na escolha dos futuros empregados era que o candidato à vaga não estivesse estudando. A esse respeito, Cordélia ${ }^{13}$ esclarece que,

\begin{abstract}
"Mesmo que o menino estudasse, o empresário contratava, mas não liberava antes da primeira aula. Às vezes ele [o menino] chegava na escola na segunda ou terceira aula, sem tomar banho e sem comer; passava em casa só pra mudar de roupa e ia pra escola, porque o patrão não liberava. E quando ele [o empresário] podia rejeitar o menino [estudante], se tinha outro pra assumir a vaga, ele rejeitava. Porque, pra ele [o empresário], era mais vantajoso o que não estudava”.
\end{abstract}

Continuando seu depoimento, Cordélia revela quanto a desvalorização da escola está presente na família. Segundo ela,

"Aqui [em Jardim], os pais não valorizam a escola. O menino que quiser estudar, estuda, mas se não quiser, os pais não obrigam. Os pais entendem que, pra ganhar dinheiro, não precisa saber. Tem as tecelagens, as estamparias, o comércio informal, não precisa saber. $\mathrm{O}$ promotor anterior [na cidade até meados de 2000] indiciou vários pais, porque as crianças se evadiam da escola e eles não tomavam providências, eram até coniventes com isso. Depois da ação do promotor, por força da justiça, os pais começaram a colocar os filhos na escola, mas eles não valorizam o ensino. $\mathrm{Na}$ minha própria casa, quando eu vou orientar meus filhos sobre a necessidade de estudar, eles dizem - mãe, você tem duas formaturas mas não ganha dinheiro, enquanto fulano de tal, que é analfabeto, é rico! - E aí vão dizer os bens que a pessoa tem. As crianças vão trabalhar porque elas querem o dinheiro pra entrar na boate, pra comprar roupa de marca. Os adolescentes já se sentem poderosos, e vão ficando mais poderosos e aí começam com as drogas, com a prostituição".

Expressão do sentido particular que assume o trabalho no capitalismo, esse evidente desinteresse pela escola e subordinação ao trabalho, de acordo com Mészáros (1995), não passaria de um epifenômeno da subsunção do trabalho pelo capital. Neste sentido os adolescentes, inclusive, chegam a zombar dos professores, os quais, segundo eles, apesar dos anos de estudo, não ganham salários suficientes para uma vida tranqüila, ao contrário de muitos analfabetos, que são empresários ricos. Contraditoriamente, tal subordinação se insere na atual lógica da produção capitalista, marcada pelo desemprego estrutural e pela diminuição do emprego de trabalho variável, cuja crescente competitividade entre os trabalhadores para se inserirem nos postos disponíveis vale-se do requisito da escolarização, nos termos da teoria do capital humano.

\section{CONCLUSÃO}

13 Cordélia é nutricionista, tendo estado envolvida diretamente como coordenadora de programa de atendimento a crianças retiradas do trabalho, em Jardim de Piranhas.
Não é fácil visualizar todas as relações envolvidas numa realidade complexa, que apresenta uma teia de fatores interagindo e afetando uns aos outros. 
Ressalte-se, no entanto, que a exploração do trabalho produtivo de crianças e adolescentes, observada em contextos de precarização das famílias, possibilita o aumento da renda familiar, por um lado, e o crescimento do lucro do empresário, por outro. Nesse contexto, a despeito da contribuição para o aumento da renda da família, o trabalho não só não contribui para superar o estado de miséria em que elas se encontram, como reproduz as condições de perpetuação da pobreza.

Em relação aos impactos dessa exploração, procuramos mostrar que a condição a que estão submetidos crianças, adolescentes e suas famílias traz como consequiência uma rearrumação das relações estabelecidas, seja no interior dessas famílias, seja na dinâmica do próprio município.

Pensando-se no desenvolvimento humano, a realidade observada em Jardim de Piranhas, do trabalho precoce, evidenciada pelos depoimentos dos sujeitos entrevistados, ilustra como este fato pode ter efeitos danosos para as crianças e adolescentes, afetando, principalmente, sua saúde, seu processo de escolarização e de formação da sua identidade.

Expressão do apetite desmedido do capital e da falta de políticas consistentes, voltadas para a criança e o adolescente, o trabalho precoce também exprime a força da "ideologia ou valorização do trabalho, que o mostra como dignificante, como escola, almejado pelos pais porque afasta a criança da rua e da marginalidade" (Jornal do Cress, 1996). Não obstante a ampla divulgação, desde pelos menos um século atrás, dos prejuízos advindos do exercício do trabalho precoce em atividades produtivas, seu combate encontra barreiras de porte, seja nas próprias vítimas da situação seja nas suas famílias, em face da força dessa ideologia, que se alimenta da luta pela sobrevivência.

\section{REFERÊNCIAS}

Azevedo, M. A. \& Marques, M. L. (Orgs.). (1994). Alfabetização hoje. São Paulo: Cortez Editora.

Biaggio, A. M. B. (1988). Psicologia do desenvolvimento. Petrópolis: Vozes.

BRASIL. (1998). Ministério da Educação e do Desporto. Secretaria de Educação Fundamental. Referencial curricular nacional para a educação infantil. (3 Vol.) Brasília: MEC/SEF.

BRASIL. (1998a.). Ministério do Trabalho e Emprego. Delegacia Regional do Trabalho e Emprego no Rio Grande do Norte. Projeto "Empregador legal, trabalhador cidadão", indústria têxtil de Jardim de Piranhas/RN. Natal/RN. (relatório de agosto a outubro de 1998.)
BRASIL. (1999). Ministério do Trabalho e Emprego. Grupo Técnico Nacional e Organização Internacional do Trabalho. Investigação dos comprometimentos do trabalho precoce na saúde de crianças e adolescentes: relatório final de pesquisa. Brasília: DF.

BRASIL. (1999a). Instituto Brasileiro de Geografia e Estatística. Pesquisa nacional por amostragem domiciliar. Brasília. DF.

Bronfenbrenner, U. (1992). Ecological systems theory. London: Jessica Kingsley Publishers.

Bronfenbrenneer, U. (1996). A ecologia do desenvolvimento humano: experimentos naturais e planejados. Porto Alegre: Artes Médicas. (Original publicado em 1979).

Bruner, J. S. (1965). The course of cognitive growth. American Psychologist, 15 (1), 1-15.

Campos, H. R. (2001). Pobreza e trabalho infantil sob capitalismo. Tese de Doutorado, Universidade Federal do Rio Grande do Norte, Natal.

Coll, C., Palacios, J. \& Marchesi, A. (1995). Desenvolvimento psicológico e educação . Psicologia Evolutiva (Vol. 1). Porto Alegre: ArtMed.

Dulles, J.W. F. (1977). Anarquistas e comunistas no Brasil, 1900-1935. Rio de Janeiro: Nova Fronteira.

Engels, F. (1986). A situação da classe trabalhadora na Inglaterra. São Paulo: Global.

Ferreiro, E. (1992). Com todas as letras. São Paulo, Cortez.

Flavell, J. H. (1975). A psicologia do desenvolvimento de Jean Piaget. São Paulo: Pioneira.

Jobim e Souza, S. (1996). Re-significando a psicologia do desenvolvimento: uma contribuição crítica à pesquisa da infância. Em S. Kramer \& M. I. Leite (Orgs), Infância: Fios e desafios da pesquisa. (pp. 39-55). Campinas: Papirus.

JORNAL DO CRESS. (1996, novembro). Natal.

Klein, L. R. (1997). Alfabetização: quem tem medo de ensinar? (2 ${ }^{\text {a }}$ ed.) São Paulo: Cortez Editora/ Editora UFMS.

Kramer, S. (1994). A formação do professor como leitor e construtor do saber. Em A. F. Moreira (Org.), Conhecimento educacional e formação do professor. Campinas: Papirus.

Marx, K. (1996). O capital: crítica da economia política. Livro 1: O processo de produção do capital. (Vol. 1.) Rio de Janeiro: Bertrand Brasil. (Original publicado em 1867).

Mészáros, I. (1995). Beyond capital. (Towards a theory of transition). Londres: Merlin Press.

Piaget, J. (1964). La formation du symbole chez l'enfant: imitation, jeu et rêve, image et representation. Neuchatel/Suisse: Éditions Delachaux et Niestlé. Troisième édition.

Pochman, M. \& Amorim, R. (2003). Atlas da exclusão social no Brasil. São Paulo: Cortez.

Vygotsky, L. (1981). The genesis of higher mental functions. In J. V. Wertsch (Ed.). The concept of activity in Soviet psychology. (pp. 144-188.) Armonk, NY: M. E. Sharpe.

Vygotski, L. (1981). A formação social da mente. São Paulo: Martins Fontes.

Vigotski, L. S., Luria, A. R. \& Leontiev, A. N. (1988). Linguagem, desenvolvimento e aprendizagem. São Paulo: Ícone / EDUSP. 
Vygotski, L. (1996). Teoria e método em psicologia. São Paulo: Martins Fontes

Vygotski, L. (1997). Pensée e langage. Paris: La Dispute. (Original publicado em 1934).

Wallon, H. (1975). Objectivos e métodos da psicologia. Lisboa: Editorial Estampa.

Wallon, H. (1979). Psicologia e educação da criança. Lisboa: Veja/Universidade.
Winnicott, D. W. (1982). A criança e seu mundo. Rio de Janeiro: Zahar.

Recebido em 23/01/2003

Revisado em 11/04/2003

Aceito em 30/05/2003 